\title{
Helium: Is the Sky the Limit?
}

The concept of helium, specifically a helium/oxygen mixture (heliox), as a medical therapy was first suggested by Barach in 1934 as a way to improve air flow in patients with airway obstruction from asthma and obstructive lesions. ${ }^{1}$ Due to the impact of World War II, heliox was largely forgotten until the 1970s. Since its re-introduction, studies examining the use of heliox have been controversial and have yielded largely conflicting findings regarding its utility, as well as questions regarding the validity of data. Unfortunately, the lack of clear evidence in support of heliox has limited its clinical popularity and precluded specific guidelines regarding its use, though it remains on the formulary at many major centers.

The major benefit of helium mixtures comes from the low density of helium compared with air and oxygen, which favors laminar flow, reduces airway resistance, and improves respiratory mechanics with decreased work of breathing and energy expenditure. ${ }^{2}$ Moreover, helium is an inert gas, which makes the likelihood of any adverse effects from its use incredibly small. ${ }^{3}$ Because of its theoretical benefit and favorable side-effect profile, and despite the aforementioned lack of evidence, the use of heliox has been advocated in many respiratory conditions, including upper airway obstruction, extrinsic upper airway compression, postextubation stridor, croup, laryngotracheomalacia, bronchiolitis, ARDS, and obstructive lung disease.

In this issue of Respiratory CARE, Leatherman et $\mathrm{al}^{4}$ present a single-center prospective observational study assessing the impact of 30 min of heliox (70:30 helium: oxygen) on airway pressures (peak, plateau, and total PEEP) as well as $\mathrm{P}_{a C O}$ in intubated subjects with severe airway obstruction (COPD and asthma). Unlike previous studies, these authors showed no difference in indices of hyperinflation, including plateau pressure and PEEP. The authors explain their findings physiologically on the basis of the principle that heliox only im-

\footnotetext{
The authors have disclosed no conflicts of interest.
}

Correspondence: Amanda M Kleiman MD, University of Virginia Health System, PO Box 800710, Charlottesville, VA 22908. E-mail: ak8zg@hscmail.mcc.virginia.edu.

DOI: $10.4187 /$ respcare. 06200 proves areas of turbulent air flow, and therefore, if air flow is already laminar, no improvement would be expected with heliox. Based on the evidence from this

See the Original Study on Page 375

study, the authors conclude that there is limited clinical benefit of heliox in patients with obstructive lung disease.

Should heliox be written off completely, or is it being unfairly judged? While improvements in hyperinflation and other respiratory parameters appear unclear, the benefits of heliox in patients with severe obstructive pulmonary disease and other pathologies may exist beyond the effects studied here. In a similar ICU population, a recently published multi-center randomized trial in Europe and Canada examined whether $72 \mathrm{~h}$ of heliox during and between episodes of noninvasive ventilation reduced the rate of failure of noninvasive ventilation requiring intubation. ${ }^{5}$ Although the study was stopped early due to a low failure rate in both groups, heliox was associated with significantly faster improvement of breathing frequency, acidosis, hypercapnia, and encephalopathy. Some of these effects are likely due to improved gas exchange seen with helium due to the more favorable diffusion of carbon dioxide $(4-5 \times)$ compared to air. Additionally, of the subjects who had failure of noninvasive ventilation, those receiving heliox had a shorter duration of mechanical ventilation and ICU length of stay, potentially due to improved respiratory mechanics, less muscle fatigue, and enhanced ventilator weaning. ${ }^{5}$

A key role of heliox in the treatment of obstructive lung disease is as a vehicle for the administration of bronchodilators. Delivery of bronchodilators to more compromised distal airways via conventional methods is difficult because airway obstruction causes preferential delivery to central, less affected airways. Heliox promotes a more uniform deposition in the central and peripheral airways, improving delivery to the most affected areas that limit air flow. ${ }^{6}$ Heliox-driven delivery of bronchodilators is particularly useful in acute asthma and COPD exacerbations, resulting in enhanced improvement in all spirometry parameters compared with oxygen. ${ }^{7}$ Bronchodilator administration with heliox is also useful in stable asthmatics, producing improvements in $\mathrm{FEV}_{1}$ as well as inspiratory capacity. ${ }^{6}$ 


\section{EDITORIALS}

Amelioration of symptoms and improved physical activity are crucial parts of the treatment of COPD and contribute to an improved sense of well-being. This may ultimately be one of the primary indications for heliox therapy. Patients with obstructive lung disease experience worsening of symptoms during exercise as they struggle to increase ventilation primarily through changes in breathing frequency. As breathing frequency increases, inspiratory and expiratory times decrease. Shortening inspiratory and expiratory times favors turbulence, which reduces expiratory flow and inspiratory and expiratory volumes, and also worsens hyperinflation (dynamic hyperinflation). Unlike the physiology described by Leatherman et al, ${ }^{4}$ in the presence of turbulent flow, as seen with exercise, heliox improves respiratory mechanics. Therefore, heliox has clinical benefit when used in the out-patient treatment of obstructive lung disease as a part of pulmonary rehabilitation. By promoting laminar flow and limiting dynamic hyperinflation, heliox significantly increases the amount of time patients with COPD are able to exercise. ${ }^{8}$ In addition to increased exercise duration, several other studies support improved intensity of exercise, including walk distance, with the use of heliox. ${ }^{9}$

Responses to heliox appear to be somewhat variable in that patients with more severe disease, and those with disease of the proximal airways where turbulent flow is more prevalent are more responsive to heliox therapy. ${ }^{10}$ It is fortunate that the respiratory effects of heliox are seen within 30-60 min, so individual responses to heliox can be determined quickly. It is logical to recommend a brief trial of heliox in patients who might have an improvement with heliox.

Moreover, helium has other physiologic effects outside of its impact on pulmonary physiology. In the cardiovascular system, helium has a synergistic effect with nitric oxide on pulmonary vasculature, resulting in decreased mean pulmonary artery pressure. ${ }^{11}$ The mechanism for this effect may be similar to that seen with bronchodilators with regard to improved small-airway delivery of nitric oxide. Helium is also cardioprotective, activating pro-survival signaling kinases while inhibiting mitochondrial permeability transition. ${ }^{12}$ Helium decreases infarction size when used as an agent for both cardiac pre- and post-conditioning. ${ }^{13}$ Similar to the myocardium, helium also has neuroprotective effects, possibly due to denitrogenation, and several studies have shown decreased infarction size and improvement of neurologic deficits compared to other treatments, including hyperoxia in both traumatic brain injury and stroke models. ${ }^{14}$

Helium is also proving useful to improve procedural and imaging aspects of medicine. Helium may be used as an alternative to carbon dioxide for insufflation in increasingly common laparoscopic and robotic proce- dures. ${ }^{14}$ Compared with carbon dioxide insufflation, helium is associated with less hypercarbia and associated respiratory acidosis, making it particularly appealing for use with patients with cardiopulmonary disease, including COPD. ${ }^{15}$ Hyperpolarized helium has shown promise in optimizing imaging of lung tissue with magnetic resonance imaging (MRI). Lung MRI has long been challenging due to air-tissue interfaces, cardiorespiratory motion, and the lack of hydrogen in the lung fields. However, by utilizing hyperpolarized helium, MRI images are improved, enabling clinicians to gain valuable information about oxygenation and to display airway obstruction and changes over time in patients with obstructive lung disease. ${ }^{16}$

Despite the lack of positive findings regarding indices of hyperinflation in the population of intubated subjects with COPD and asthma studied by Leatherman et $\mathrm{al},{ }^{4}$ heliox appears to have many potential clinical benefits, and medical applications for helium continue to evolve. Unfortunately, comparatively few studies on heliox have been published, with many of these being observational in nature. As with many relatively new therapies, additional larger, randomized controlled studies are needed to fully elucidate the effects of heliox in different patient populations before the final verdict on heliox (and helium) is handed down.

\section{Amanda M Kleiman MD Julie L Huffmyer MD University of Virginia Charlottesville, Virginia}

\section{REFERENCES}

1. Barach AL. Use of helium as a new therapeutic gas. Proc Soc Exper Biol Med 1934;32:462-446.

2. Papamoschou D. Theoretical validation of the respiratory benefits of helium-oxygen mixtures. Respir Physiol 1995;99:183-190.

3. Harris PD, Barnes R. The use of helium and xenon in current clinical practice. Anaesthesia 2008;63:284-293.

4. Leatherman J, Romero R. Lack of benefit of heliox during mechanical ventilation of patients with severe airflow obstruction. Respir Care 2018;63(4):375-379.

5. Jolliet P, Ounaes-Besbes L, Abroug F, Ben Khelil J, Besbes M, Garnero A, et al. A multicenter randomized trial assessing the efficacy of helium/oxygen in severe exacerbations of chronic obstructive pulmonary disease. Am J Respir Crit Care Med 2017;195(7): 871-880.

6. Alcoforado L, Brandão S, Rattes $\mathrm{C}$, Brandão $\mathrm{D}$, Lima V, et al. Evaluation of lung function and deposition of aerosolized bronchodilators carried by heliox associated with positive expiratory pressure in stable asthmatics: a randomized clinical trial. Respir Med 2013;107(8):1178-1185.

7. Kress JP, Noth I, Gehlbach BK, Barman N, Pohlman AS, Miller A, et al. The utility of albuterol nebulized with heliox during acute asthma exacerbations. Am J Respir Crit Care Med 2002;165(9): 1317-1321. 


\section{EDITORIALS}

8. Eves ND, Sandmeyer LC, Wong EY, Jones LW, MacDonald GF, Ford GT, et al. Helium-hyperoxia: a novel intervention to improve the benefits of pulmonary rehabilitation for patients with COPD. Chest 2009;135(3):609-618.

9. Hunt T, Williams MT, Frith P, Schembri D. Heliox, dyspnoea, and exercise in COPD. Eur Respir Rev 2010;19(115):30-38.

10. Levy SD, Alladina JW, Hibbert KA, Harris RS, Bajwa EK, Hess DR. High-flow oxygen therapy and other inhaled therapies in intensive care units. Lancet 2016;387(10030):1867-1878.

11. Nie M, Kobayashi H, Sugawara M, Tomita T, Ohara K, Yoshimura H. Helium inhalation enhances vasodilator effect of inhaled nitric oxide on pulmonary vessels in hypoxic dogs. Am J Physiol Heart Circ Physiol 2001;280(4):H1875-H1881.

12. Pagel PS, Krolikowski JG, Shim YH, Venkatapuram S, Kersten JR, Weihrauch D, et al. Noble gases without anesthetic properties protect myocardium against infarction by activating prosurvival signaling kinases and inhibiting mitochondrial permeability transition in vivo. Anesth Analg 2007;105:562-569.

13. Oei GT, Huhn R, Heinen A, Hollmann MW, Schlack WS, Preckel B, Weber NC. Helium-induced cardioprotection of healthy and hypertensive rat myocardium in vivo. Eur J Pharmacol 2012;684(1-3):125131.

14. Berganza CJ, Zhang JH. The role of helium gas in medicine. Med Gas Res 2013;3:18.

15. Cheng Y, Lu J, Xiong X, Wu S, Lin Y, Wu T, Cheng N. Gases for establishing pneumoperitoneum during laparoscopic abdominal surgery. Cochrane Database Syst Rev 2013;1:CD009569.

16. de Lange EE, Altes TA, Patrie JT, Parmar J, Brookeman JR, Mugler JP 3rd, Platts-Mills TA. The variability of regional airflow obstruction within the lungs of patients with asthma: assessment with hyperpolarized helium-3 magnetic resonance imaging. J Allergy Clin Immunol 2007;119:1072-1078. 